\title{
A Visco-hypoplastic Constitutive Model for Rolled Asphalt
}

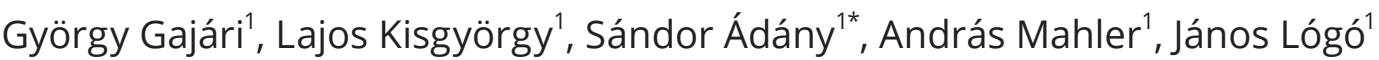 \\ ${ }^{1}$ Faculty of Civil Engineering, Budapest University of Technology and Economics, H-1521 Budapest, P.O.B. 91, Hungary \\ * Corresponding author, e-mail: sadany@epito.bme.hu
}

Received: 14 November 2020, Accepted: 10 February 2021, Published online: 22 March 2021

\begin{abstract}
Experience has shown that the durability of "high-modulus" asphalts made with modified bitumen is unsatisfactory. The misdirected "development" forced in recent decades necessitates a more accurate understanding of the mechanical behavior of rolled asphalts, i.e., constitutive formulation of a numerical asphalt model. The authors elaborate a numerical procedure to model the visco-hypoplastic constitutive behavior of the rolled asphalts by the appropriate composition of the hypoplastic theory of soil mechanics and, taking into account the existing asphalt models. This proposal is justified because rolled asphalt is nothing more than an aggregate skeleton of mineral origin, the voids of which are filled with high-viscosity bitumen. The model allows to quantify the interaction of the two components, such as the formation of ruts due to pressure on the bitumen, the formation of cracks due to cooling-induced tensile stresses, and the viscous behavior of asphalt. Validity of this complex numerical model can already be considered proven theoretically, but it still needs to be experimentally verified for the viscous behavior. This new constitutive model has important theoretical and practical consequences such as a new visco-hypoplastic model of rolled asphalt as partially saturated granular material with coolinginduced isotropic residual stresses.
\end{abstract}

\section{Keywords}

constitutive model, rolled asphalt, pavement, hypoplasticity, visco-hypoplasticity, residual stresses

\section{Introduction}

Asphalt, as a structural material, is one of the most commonly used building materials for pavement constructions. This material, which seems homogeneous in its name but is in fact a complex material, can be described by very complicated mathematical equations. The relationship between stress-strain is affected not only by the magnitude of the load, but also by its velocity, number of repetitions, but also by temperature and elapsed time. Furthermore, during the construction of the pavement structure, the asphalt is compacted and layered. The quality and construction of the compaction itself largely determines the quality, service life, and stress-strain relationship of the pavement structure. The material equations for asphalt, the implementation of compaction, the number of layers and their thickness are mainly based on the results of experimental and empirical studies. In the following, we present the known numerical models through some papers.

It is widely known that the asphalt mixture is a complex heterogeneous material composed of three components, a visco-elasto-plastic matrix (mastic) combined with a rigid-plastic skeleton of granular inclusions and containing a given percentage of air voids. In this medium, the crushed aggregates display very irregular shapes, complex angularity, and a wide range of sizes. The smallest grain measures only a few micrometers in diameter, while larger grain diameters lie in the range of tens of millimeters.

A common feature of the existing asphalt models is that in rolled asphalt, the aggregates form a three-dimensional skeleton, as opposed to mastic asphalt where the aggregates partly float in the bitumen and therefore have less influence on the strength and stiffness properties of the asphalt.

The analogy of rolled asphalt and unsaturated sand is showed in Fig. 1. This analogy is based on the following observations:

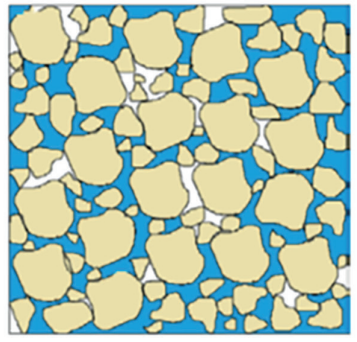

(a)

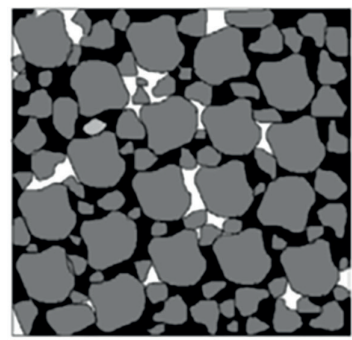

(b)
Fig. 1 Analogy of (a) unsaturated soil and (b) rolled asphalt 
- sand (soil) and asphalt consist of granular material of mineral origin,

- in the case of unsaturated sand, the (apparent) cohesion that results in strength is created by surface tension forces in pore water. In the case of asphalt, this corresponds to the cooling-induced shrinkage of bitumen, which causes isotropic residual stresses in the material pressing the particles together,

- fine-grained soils (silt, clay) also show viscous behavior; for these the water serves as a lubricant, while in the case of asphalt, this role is played by the bitumen by lubricating the contact surfaces of the particles.

Each of the existing asphalt models is based on plasticity models developed for soils. One can follow these models by overviewing the following selected papers (Fellin [1], von Wolffersdorff [2], Kolymbas [3], Niemunis and Herle [4], Fellin and Ostermann [5], Mašín [6], Bauer [7]).

Understanding the mechanics of asphalt is the same as setting up a constitutive model correctly describing its mechanical behavior. The mathematical formulation is the material model of the asphalt, which should be consistent with the observations that characterize the behavior of asphalt. Formulation of the model should start from these observations. The model must then be able to naturally describe the observed phenomena. These are:

- formation of residual deformations (ruts),

- cooling-induced tensile stresses and crack formation,

- frequency, temperature and stress dependency of the modulus.

Due to the lack of fundamental research, the development in recent decades has been mainly focused on the binder. The role of bitumen was badly overrated without the mechanical behavior of the asphalt being precisely clarified. Development has shifted towards "high modulus", which was intended to be accomplished exclusively by bitumen. As a result, although asphalt was more resistant to the formation of ruts, it became more difficult to compact despite the higher laying temperature. Fatigue strength of the more brittle asphalt has reduced at low temperatures and aging has also accelerated [8].

Gajári $[9,10]$ has concluded that residual deformations (ruts) are caused by the excessive use of bitumen exceeding the optimum value. According to the mechanical explanation, excess pressure is created in the binder if it exceeds the optimum amount [9]. At the optimum bitumen content, the voids in the mineral aggregate are minimal during compaction. Bitumen content above the optimum value will make the aggregate skeleton susceptible to further compaction if subjected to a large number (million) of loading cycles, which would result in further decrease in the volume of voids. As a result, some or all of the pressure on the aggregate skeleton may be transferred to the bitumen having no shear strength. In the mechanics of granular materials (soil mechanics), this phenomenon has long been known (since the pioneering work of Terzaghi [11].

The second important observation and experimental result is that asphalt contracts due to cooling, which can be attributed to the cooling-induced shrinkage of bitumen.

Arand et al. [12] showed as early as the 1980s that asphalt cracks as a result of cooling if its shrinkage is limited during cooling. In the case of asphalt fatigue, tensile stresses caused by cooling should be taken into account [13]. Accumulation of the cyclic traffic loads and residual stresses cause the tensile cracks starting from the surface. Experience has shown that cracks of this type are common in high modulus asphalts. In Hungary, laboratory fatigue testing of asphalts is performed at "high" temperatures $\left(15-20^{\circ} \mathrm{C}\right)$, therefore this method is not suitable for the study of low-temperature fatigue.

Stiffness of the asphalt is also the result of cooling-induced isotropic residual stresses [10]. The Young's modulus of asphalt is by orders of magnitudes higher than that of the bitumen. In soil mechanics, it is known that the Young's modulus of granular skeleton without any confining pressure is also zero. This is because the modulus is proportional to the contact pressure between the particles in the first approximation. The measured Young's modulus of asphalt in the absence of chemical processes can only be explained by the fact that the cooling-induced volumetric shrinkage of bitumen pre-stresses the aggregate skeleton, i.e., the pressure between the particles is induced by the cooling of bitumen.

The third observation concerns the viscous behavior of asphalt. The complex moduli shown in Fig. 2 was measured by applying uniaxial sinusoidal loading to cylindrical samples [14]. The imaginary part of the complex modulus represents the viscous stiffness of the asphalt. This explains the velocity (frequency) and temperature dependence. It is customary to assume that the principle of time-temperature superposition is valid for the complex modulus, according to which the modulus measured at different temperatures can be converted to a reference temperature by changing the frequency accordingly. However, the measurement by Gajári shown on cylindrical samples in Fig. 3 disputes the validity of this principle [9]. The complex modulus was measured on a torsional sample using 
different pressures acting in the direction of axis "1-longitudinal axis-". In the direction of the radial axes "2" and "3", the deformation was limited to zero, so the stress state of the sample was three-dimensional. Figs. 3 shows that the complex stiffness also increases with increasing pressure. The modulus is therefore not only a function of temperature and frequency but also of pressure.

This principle of equivalence may seem to be true for uniaxial harmonic loading, because in that case different pressures cannot be set, so the pressure dependence is not revealed. It is known from soil mechanics that stiffness and strength of granular materials cannot be tested in a uniaxial stress state.

\section{Overview of the existing models}

Tehrani et al. [15] present modeling of an asphalt pavement structure by estimating the dynamic modulus of elasticity of a porous asphalt mixture. The test material is modeled as a two-phase medium in that it consists of particulate inclusions with a linearly elastic property and a bituminous adhesive with a given percentage of air content $(5-6 \%$ in their article). Thus, they can describe linear deformations in the case of small deformations. The model is subjected to a cyclic load at a given load frequency. The generalized Maxwell model was used to determine the viscoelastic behavior of the material.

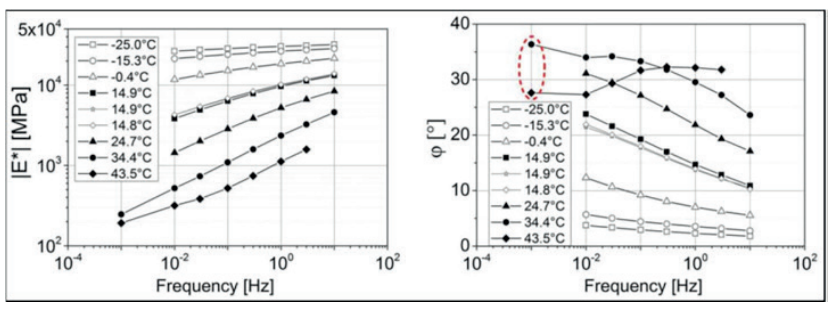

Fig. 2 Complex modulus and phase angle of asphalt at different frequencies and temperatures

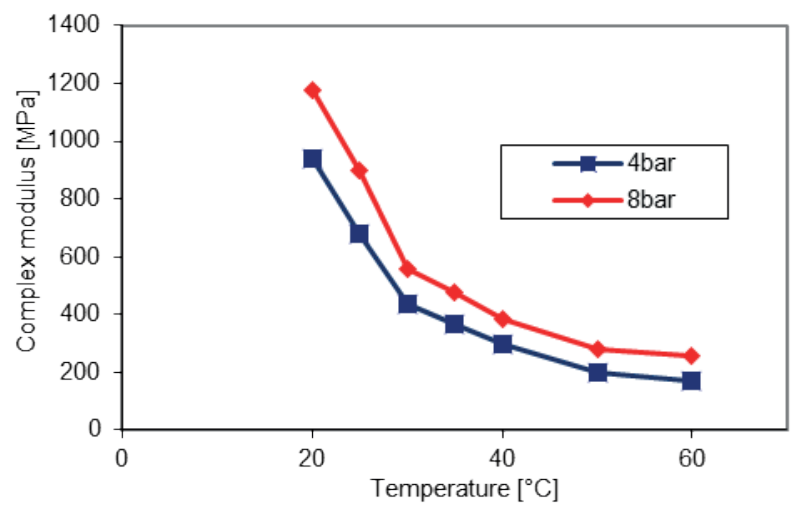

Fig. 3 Complex modulus of asphalt at different pressures and temperatures
El Haloui et al. [16] show a numerical modeling of the formation and propagation of cracks in asphalt.

Iskakbayev et al. [17] present modeling of creep of linear viscoelastic materials using Boltzman-Volterra integral equations. The phenomenon of creep kernel was approximated by Rabotnov's exponential function. The creep equation contains four unknown parameters: $\alpha$ singularity parameter, $\beta$ fading parameter, $\lambda$ rheological parameter, and $\varepsilon_{0}$ conditional instantaneous deformation parameter. Their model is a two-level method for determining creep parameters. At the first level, $\alpha$ and $\varepsilon_{0}$ can be determined, and then the fading parameter $\beta$ and the rheological parameter $\lambda$ can be calculated at the second level.

Murali Krishnan and Rajagopal [18] present the determination of the constitutive equations of an asphalt pavement structure. The equations are derived on a thermodynamic basis. Their calculations show that their equations are suitable for describing constitutive behavior over a wide temperature range and at different compression pressures.

Taherkhani [19] presents the results of uniaxial and triaxial experiments on asphalts in his paper.

The mechanical behavior of asphalt mixtures is shown by Huang and Zhang [20]. New experimental procedures have been developed to investigate material parameters and rheological phenomena.

Each point of the above summary contains important details that are not necessarily known in the profession, but at the same time they should be addressed when creating a constitutive model describing the behavior of asphalt.

Aschenbrenner [21], Brodersen [22], and Gajári [9] used a version of the existing hypoplastic models of soil mechanics that was formulated by von Wolffesrsdorff [23]. The material parameters of the non-viscous model were determined according to Herle [24]. It is worth mentioning the work of ter Huerne [25], who used the Cam Clay model [26], the first plastic model developed for soils, to numerically simulate asphalt compaction. The Cam Clay model is mentioned here because the direction of plastic deformations in a given stress state is the same as the direction yielded by the hypoplastic model. This feature was also used by Niemunis [27] for the development of visco-hypoplastic material model.

The visco-plastic model of Aschenbrenner [21] and Brodersen [22] models the asphalt according to the volume ratios of the components (binder and aggregate skeleton) using the mixture theory of continuum mechanics. However, their models lack the following two features: sufficient stiffness of the asphalt, and formulation of the 
interaction of material components. The insufficient stiffness can be confirmed by experimental results, where the model stiffness fell much below the measured value [22]. It is clear, that the reason behind this is ignoring the cooling-induced shrinkage of bitumen. Due to the second shortcoming of the models, they will not predict the experimentally verified radical decrease in stiffness, as a result of the interaction between the plastic aggregate skeleton and the viscous asphalt if the bitumen content exceeds the optimum value defined by the Gajári. This may be because Terzaghi's principle of effective stress is not considered in the models.

According to Terzaghi's principle of effective stress, the effective stress carried by the soil skeleton and keeping the soil particles together is the difference between the total stress and the pressure in the pore fluid (called pore pressure). Thus, an increase in pore pressure (i.e., due to cyclic loading) is accompanied by a decrease in effective stress. Since the modulus is proportional to the effective stress, the increase in pore pressure results in a decreasing stiffness, which in turn increases the deformation and thus the accumulation of residual deformations as well.

The basic (reference) version of the hypoplastic model causes too large accumulation of deformations (ratcheting), so the version extended with intergranular strain should be used [4]. This extended model allows reversible (elastic) strains to develop due to small cyclic deformation, thus reducing the accumulation rate of residual (plastic) deformations. The hypoplastic constitutive model proposed by Niemunis and Herle [4] neglected viscosity. It is therefore unsuitable for simulating the third observation listed above. However, it is possible to take into account temperature dependent isotropic residual stresses with this model.

The last existing models that are discussed here are the Bonnier model [28] and the Delft University Asphalt Concrete Response model (ACRe model, Medani et al. [29]), which are visco-plastic models and can take into account the isotropic stress caused by cooling.

The yield surface of Bonnier's model is basically the same as the Mohr-Coulomb yield surface [28], while the ACRe model uses Desai's yield criterion [30], which was also developed for soil. In both models, the viscous strain rate is formulated using Norton's power law. Desai's yield surface, like the Cam-Clay model, belongs to the group of so-called "cap models" because they are closed in the direction of hydrostatic pressure, i.e., resistance against deformation increases due to compaction (decrease in pore volume). Both models include viscosity, and the yield surfaces are temperature dependent.
One of the components of yield surface is cohesion. The triaxial measurements showed that cohesion at $22^{\circ} \mathrm{C}$ is approx. $1 \mathrm{MPa}$ [9]. Both models introduce the concept of "pseudo-pressure", which is directly related to cohesion:

$p=\frac{c}{\tan (\varphi)}$,

where $p$ is the pseudo-pressure, $c$ is the cohesion and $\varphi$ is the friction angle.

Bonnier [28] makes the cohesion temperature dependent, however the relationship was first proposed by di Benedetto [31]:

$c=c_{r} \exp \left(3200\left(\frac{1}{T}-\frac{1}{T_{r}}\right)\right)$,

where $c_{r}$ is the reference (measured) value of cohesion, $T$ is absolute temperature; $T_{r}$ is reference (measured) value of absolute temperature.

The simultaneous validity of both relationships is equivalent to the temperature dependent pseudo-pressure, i.e., to the isotropic residual stress caused by cooling.

Bonnier [28] gave Norton's flow rule (secondary creep strain rate) in the following form:

$\dot{\varepsilon}^{v p}=\frac{1}{\tau}\left(\sigma-\sigma_{s c t}\right)^{\beta} \quad$ if $\sigma>\sigma_{s c t}$,

where $\tau$ is temperature dependent time factor, $\sigma$ is the uniaxial normal stress; $\sigma_{s c t}$ is the threshold value of secondary creep; $\beta$ is the creep exponent (material constant) and it is a constant determined experimentally. Here, for the studied asphalt, Bonnier gave $\beta=4$ for the creep exponent. The temperature dependent time factor can be obtained using the following formula:

$\tau=\tau_{r} \exp \left(16500\left(\frac{1}{T}-\frac{1}{T_{r}}\right)\right)$.

The time factor has the following values in the function of temperature:

$\tau_{r}=163000 \mathrm{sec}$ if $T_{r}=278^{\circ} \mathrm{K}\left(5^{\circ} \mathrm{C}\right)$,

$\tau_{r}=4400 \sec$ if $T_{r}=296^{\circ} \mathrm{K}\left(23^{\circ} \mathrm{C}\right)$,

$\tau_{r}=180 \sec$ if $T_{r}=314^{\circ} \mathrm{K}\left(41^{\circ} \mathrm{C}\right)$.

The viscosity law of ACRe model is analogous to that given by Bonnier. For the quantification of this rule, (secondary) creep tests with constant stress are used, the principle of which is shown in Fig. 4. 



Fig. 4 Secondary creep at different constant stresses for a given temperature (Bonnier [28])

Due to the applied creep threshold, Bonnier's model is not suitable for the study of cyclic shear-induced pore pressure generation, i.e., for the simulation of ruts. Although the Asphalt Concrete Response (ACRe) model was used for modelling compaction, it was not examined as a function of bitumen content.

It must be recognized that we will only be able to usefully intervene in the mechanical behavior of asphalt if we understand its basic mechanics. It is only after understanding its behavior that we can move forward in solving practical problems, such as:

- design of pavement structures,

- design of asphalt mixtures,

- compaction of asphalt.

It should be noted the models listed above are not suitable to describe completely the behavior of asphalt but can only model some aspects of it.

\section{Overview of the visco-hypoplastic model of soils} 3.1 The hypoplastic (non-viscous) model

Figs. 5(a-b) show the compression curves of soil by uniaxial and triaxial experiments, respectively. Oedometric compression is shown in Fig. 5(a) and the triaxial compression is in Fig. 5(b). The axis $\mathrm{x}$ is the axial strain, and the axis $y$ is the axial stress in both figures.

The diagrams perfectly illustrate that:

- the curves are not linear ones which can be approximated by linear sections,

- It is known from the literature that the curves of unloading and reloading have different path, therefore residual (plastic) strain develops due to cyclic loading,

- an important difference between the diagrams is that whereas the triaxial compression curve reaches a "limit state" (failure) where the load cannot be increased further despite additional axial compression, such a limit state cannot be reached in oedometric compression.
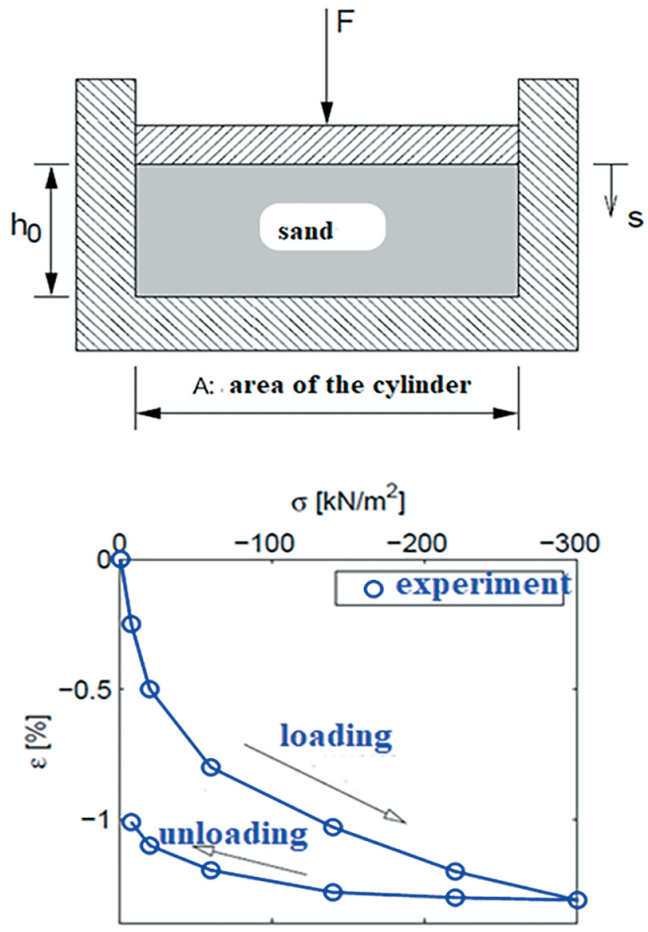

(a)
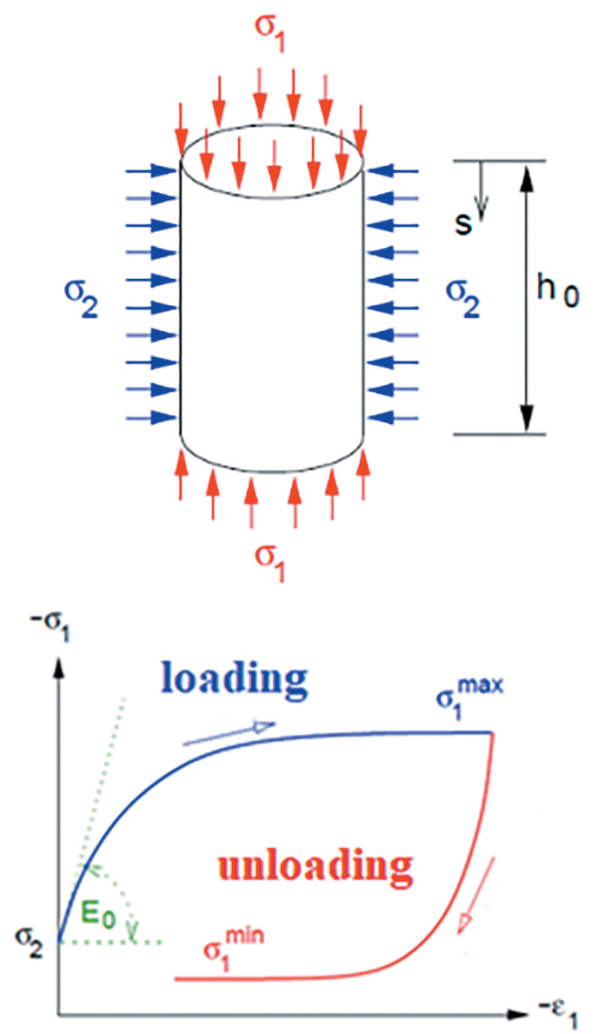

(b)

Fig. 5 Uniaxial (oedometric) and triaxial experiment and the related stress-strain diagrams (a) Uniaxial, (b) Triaxial 
The three-dimensional form of hypoplastic description is able to capture these observations in the form of a single equation $[23,27]$.

$\dot{\sigma}_{1}=L(\sigma) \times \dot{\varepsilon}_{1}+N(\sigma) \times\left|\dot{\varepsilon}_{1}\right|$,

where $\sigma$ in $L(\sigma)$ and $N(\sigma)$ represents different stress states in oedometric and triaxial compression. As a summary of the hypoplastic law:

- the equation is a differential equation, i.e., it makes a connection between the change in strain and the change in stress; the equation is numerically integrated,

- the stress change and the modulus are proportional to the stress,

- the residual strain is produced by the absolute value of the strain rate.

The constitutive equation of hypoplastic model can be found in several finite element programs [5, 32]. Hereinafter, we will use the generalized form of this equation to determine the constitutive law of asphalts. The tensor description of the generalized equations was presented by Mašín [6]. In his dissertation he presents a new constitutive model for clays. The development of the model is based on the use of generalized hypoplastic principles [33] and combines it with the theories used in traditional soil mechanics to describe critical states. The boundary curve is based on the Matsuoka-Nakai yield surface.

Based on the original hypoplastic constitutive equations, visco-hypoplastic material models were constructed [33-36]. These models assume a logarithmic stress-void ratio principle [37] and are consistent with the mechanical description of critical soil [26]. The constitutive equations presented here focus on highlighting the description of viscous behavior and can be derived from the original von Wolffersdorff [2] model.

Another application of the hypoplastic material model is the work presented by Jin et al. [38]. It is used to calculate foundations in sandy soils under monotonic and cyclic loading.

Describing the flow of debris is a very complex phenomenon from a mechanical point of view. Pore water pressure is the most important trigger in initiating debris flow. Debris materials can generally be modeled at the level of constitutive equations when treated as a solid particle-viscous liquid mixture. Guo et al. [39] used the principle of hypoplastic-viscous behavior to model the flow of debris.

\subsection{One-dimensional version of the visco-hypoplastic model}

The state-of-the-art plasticity model is the hypoplastic model, which also has a strain rate dependent version (see [34, 40]). The visco-hypoplastic model incorporates Norton's flow rule. Gajári [10] has chosen this model for the visco-plastic description of asphalt. The following equations can be written for triaxial compression:

$$
\begin{aligned}
& L=E_{0} \frac{\sigma_{1}+\sigma_{2}}{2 \sigma_{2}}, \\
& N=E_{0} \frac{\sigma_{1}+\sigma_{2}}{2 \sigma_{2}} \frac{\sigma_{1}-\sigma_{2}}{\sin \varphi\left(\sigma_{1}+\sigma_{2}\right)} .
\end{aligned}
$$

Equation (8) can be rewritten:

$\dot{\sigma}_{1}=L\left(\dot{\varepsilon}_{1}-\left(-\frac{N}{L}\left|\dot{\varepsilon}_{1}\right|\right)\right)$.

In the initial hydrostatic stress condition, $N / L=0$ due to $\sigma_{1}=\sigma_{2}$, and at failure $N / L=1$.

The sample behaves reversibly in the beginning, and ideally plastic at failure because $\dot{\sigma}_{1}=L\left(\dot{\varepsilon}_{1}-\dot{\varepsilon}_{1}\right)=0$

The residual plastic strain rate is given by $\dot{\varepsilon}_{1}^{p l}=-\frac{N}{L}\left|\dot{\varepsilon}_{1}\right|$, which is further extended to accommodate viscosity $\left(\dot{\varepsilon}_{1}^{p l}=\dot{\varepsilon}_{1}^{\text {vis }}\right)$ by the visco-hypoplastic model of Niemunis [34, 40]. Thus, the general form of the onedimensional visco-hypoplastic law is:

$\dot{\sigma}=L\left(\dot{\varepsilon}-\dot{\varepsilon}^{v i s}\right)$.

Norton's power law is adapted by Niemunis as:

$\dot{\varepsilon}^{v i s}=\dot{\gamma}\left(\frac{\sigma}{\sigma_{e}}\right)^{n}=\dot{\gamma}\left(\frac{1}{O C R}\right)^{n}$.

The exponent is a material constant, while the viscoplastic reference strain rate is temperature dependent. If the actual stress is equal to the equivalent stress, the visco-plastic strain rate will be equal to the reference strain rate.

Oedometric compression of a visco-plastic granular material is an example for the one-dimensional version of the visco-plastic material model. In Fig. 6. the stress is expressed by its logarithmic value, and the other axis is the change in void ratio.

Norton's flow rule used by Bonnier is based on Perzyna's overstress principle [41, 42]: the intensity of the visco-plastic flow is proportional to the power of the difference between the overstress and the initial yield stress if the overstress is higher than the initial yield stress $\left(\sigma>\sigma_{e}\right)[28]$. Thus, there is no viscosity in the elastic range $\left(\sigma<\sigma_{e}\right)$. Equation (13) is the modification of this rule, which does 
not show the difference in stresses but their ratio. For oedometric loading, the equivalent pressure shown in Fig. 6 represents the yield stress, which lies on the line of constant reference strain rate. The following relationship exists between the compression rate and the equivalent pressure:

$\dot{\sigma}_{e}=\frac{1+e_{0}}{C_{c}} \sigma_{e} \dot{\varepsilon}$

The $L$ elastic modulus in Eq. (13) is as follows:

$L=\frac{1+e_{0}}{C_{s}} \sigma$.

Thus, the final form of Eq. (13) is:

$\dot{\sigma}=\frac{1+e_{0}}{C_{s}} \sigma\left(\dot{\varepsilon}-\dot{\varepsilon}^{v i s}\right)$.

The set of Eqs. (14)-(16) form the model of oedometric viscous compression, which is identical to the one-dimensional version of the visco-hypoplastic material model. Due to the modification of Norton's rule, the viscous behavior is maintained even if the stress is less than the equivalent pressure, i.e., in the elastic range [34, 40]. A material model is only usable if there is a three-dimensional formulation of it. Hypoplastic and visco-hypoplastic material models are such; the three-dimensional versions are discussed in detail in the works of von Wolffersdorff [23] and Niemunis [34].

In mechanics the viscos behaviour of solids can be described by the use of Maxwell's model or Bingham's model. The constitutive equation of the Maxwell's model is similar to Eq. (16). The difference is that while in the Maxwell's model, the viscosity is constant, in Eq. (16), the viscous strain rate is proportional to the $n^{\text {th }}$ power of

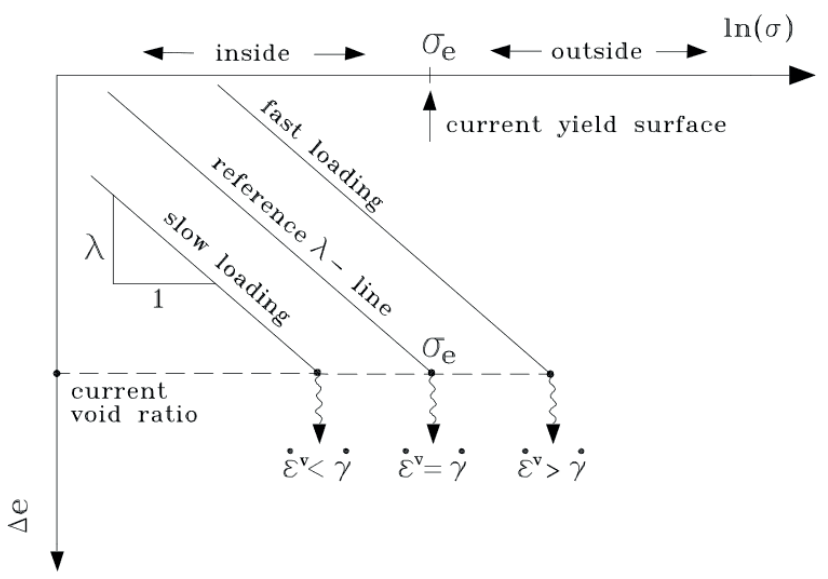

Fig. 6 Void ratio in function of compression stress at different strain rates (Niemunis and Krieg [40]) the stress, i.e., viscosity is not constant but increases as stress and strain rate decreases. These relationships are shown in Fig. 7.

As long as the stress or strain rate is not too small, the constitutive behavior of the Maxwell's model can be considered similar to Eq. (15) in intervals, only the variable viscosity should be replaced in case of the Maxwell's model.

For harmonic loading, the complex modulus of the Maxwell model [9] can be given as follows:

$$
\begin{aligned}
& S^{*}=\left|S^{*}\right| \cos \delta+i\left|S^{*}\right| \sin \delta, \\
& S^{*}=E \cos ^{2} \delta+i \omega \mu \sin ^{2} \delta .
\end{aligned}
$$

Moreover, the following equations is also valid [9]:

$$
\tan \delta=\frac{\sin \delta}{\cos \delta}=\frac{E}{\mu \omega}=\frac{1}{\omega t_{r}},
$$

$t_{r}=\frac{\mu}{E}$.

These relationships show that the phase angle decreases with increasing frequency and the complex stiffness approaches the value of Young's modulus. If the frequency decrease to zero, viscous behavior will start to dominate, and stiffness will also decrease to zero.

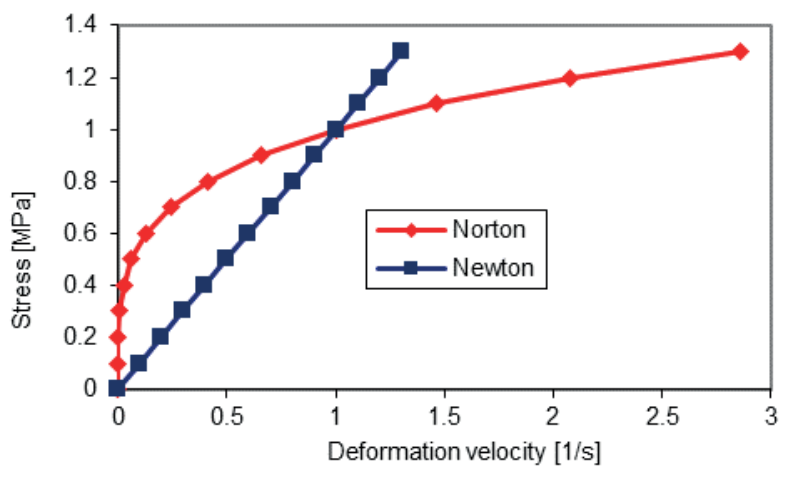

(a)

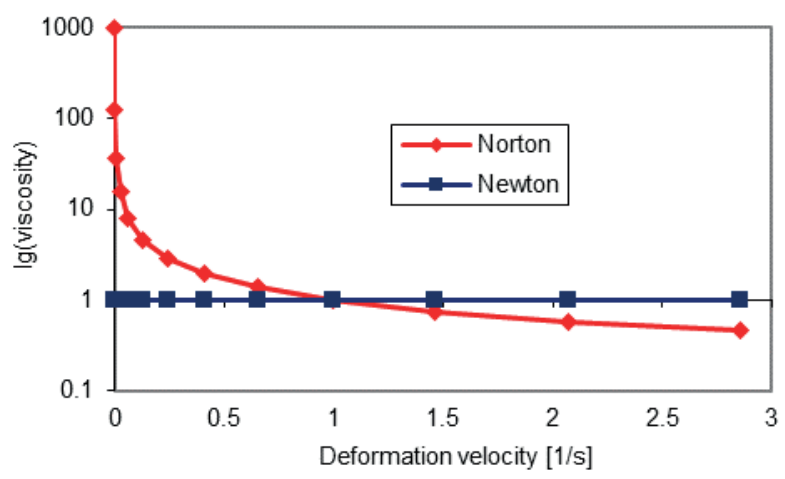

(b)

Fig. 7 Norton's and Newton's models (a) Stress, (b) Viscousity 
The first statement is also true for the visco-hypoplastic material model represented by Eq. (16), but the second is not, since decreasing frequency also means decreasing strain rate. As shown in Fig. 7, at a rate approaching zero, the viscosity increases faster than the rate decreases, the relaxation time also increases, resulting in a decrease in the phase angle. At very low frequencies, the viscohypoplastic model begins to resemble the Bingham model, which behaves elastically when the stress is less than the yield stress.

\section{Application to asphalt}

Observations show that temperature has a decisive influence on the mechanical behavior. It should be decided depending on the temperature which version of the hypoplastic models can be used for the numerical simulation of a given problem.

It is known from the work of di Benedetto [31] and Bonnier [28] that viscosity decreases strongly with temperature. The degree of this decrease is so large that viscosity even becomes negligible. ter Heurne [25] used the plastic (non-viscous) Cam-Clay material model for finite element simulation of rolling compaction. Gajári has demonstrated that the non-viscous hypoplastic material model is suitable for simulating the formation of ruts. By taking into account the pore pressure, the reduction in stiffness at high temperatures caused by cyclic loading due to the excessive use of bitumen and the increased accumulation of residual deformations could be modelled.

The above review of existing models has shown that the Bonnier and ACRe models take into account the cooling-induced isotropic residual stresses when calculating strength (cohesion) and modulus [28, 30]. Bonnier also gave the dependence on absolute temperature as derived by Benedetto. Gajári has shown using his triaxial test results that the value of cohesion for an AC 11 asphalt concrete is $1.23 \mathrm{MPa}$ at $22^{\circ} \mathrm{C}$. The temperature dependent isotropic residual stress was also calculated (Fig. 8) by taking into account the friction angle $\left(\sim 40^{\circ}\right)$. For verification purpose, it can be compared with the tensile strength obtained by Arand [13]. The agreement is satisfactory in the temperature range of 20 to $-10^{\circ} \mathrm{C}$. The question is whether the non-viscous hypoplastic model can take into account the isotropic residual stress caused by cooling. The answer is a firm yes. It is well known that the modulus of both onedimensional models is a function of the stress state and the isotropic pressure. The isotropic residual stress, as an input can be taken into account not only in the one-dimensional but also in the general three-dimensional case $[1,23]$.
In order to illustrate the effect of the cooling caused residual stress, numerical simulations of unconfined compression tests were performed. Hypoplastic material model [23] was used and parameters obtained by earlier tests [9] were applied in the simulations. By the use of our parametric study the residual stress values at different temperatures were obtained based on Fig. 8(a). The results (Fig. 8(b)) correlate well with the presumed tendencies: both the unconfined compressive strengths and the Young's moduli are increasing with decreasing temperature (increasing "pseudo pressure").

The only thing remained is the analysis of visco-hypoplastic material model. Section 2 discusses the temperature dependence of the time factor used by Bonnier [28] and derived by Benedetto [31]. This function is shown in Fig. 9(a) (left). Fig. 9(b) shows the results of creep tests [28]. In [9] Gajári assumed that the parameters of Eq. (11) defined by Niemunis correspond to the parameters of Bonnier's equation, i.e.:

$$
\begin{aligned}
& \beta=n=4=\text { constant }, \\
& \frac{1}{\tau} \approx \dot{\gamma} .
\end{aligned}
$$

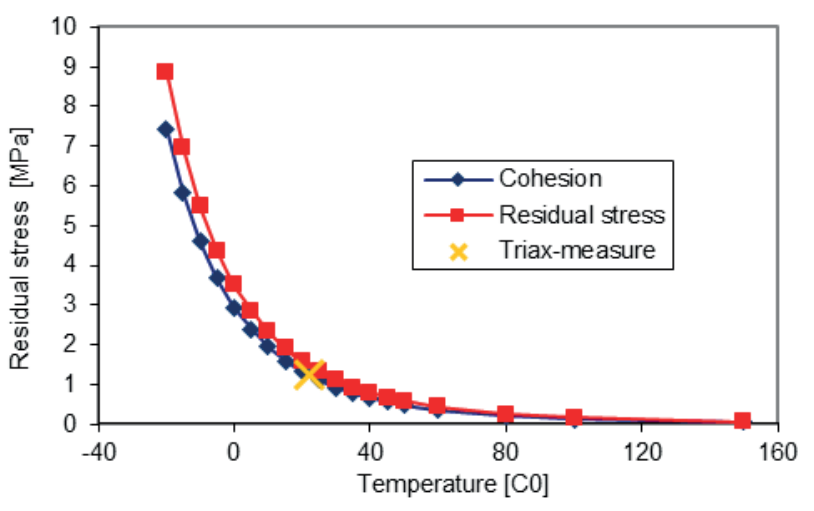

(a)

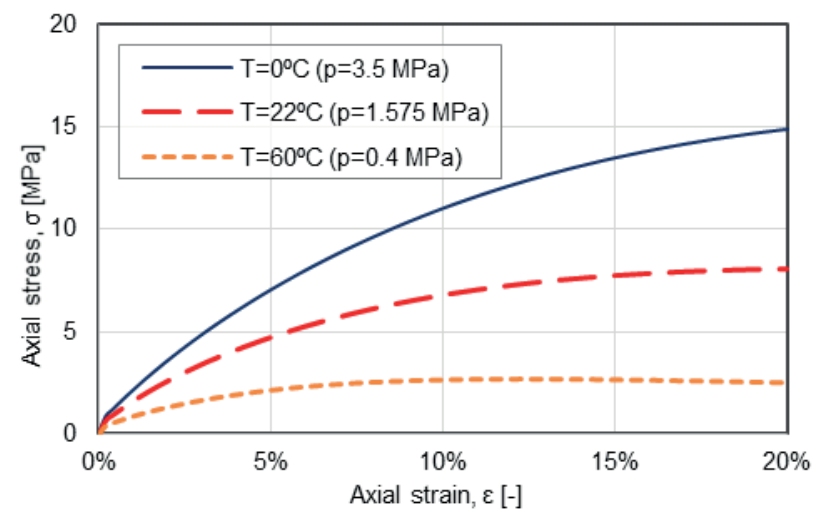

(b)

Fig. 8 Simulation of unconfined compression tests considering different temperatures (a) Temperature dependent residual stress, (b) Temperature dependent stress-strain relationship 


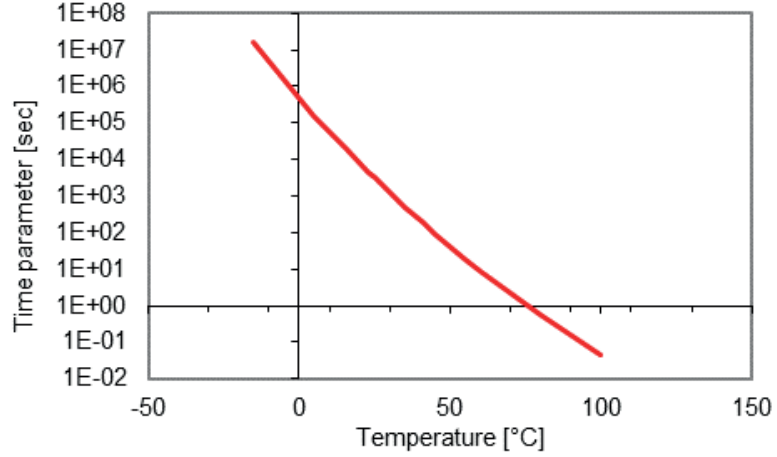

(a)

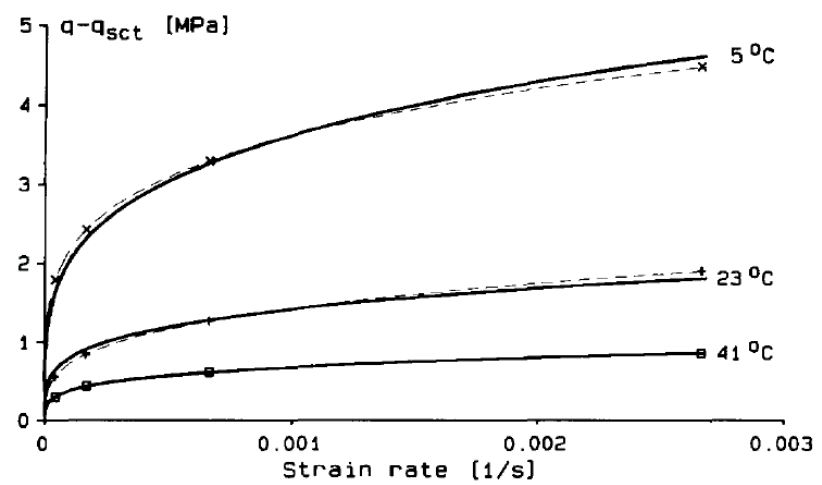

(b)

Fig. 9 Temperature dependent creep (a) Time factor, (b) Stress [28]

According to the second relationship, the reference strain rate depends on the temperature in the same way as the reciprocal of the time parameter. These assumptions can be used to calculate the ratio of the stresses to achieve the same strain rates at different temperatures:

$\dot{\varepsilon}^{v i s}=\frac{1}{\tau_{1}\left(T_{1}\right)}\left(\frac{\sigma_{1}\left(T_{1}\right)}{\sigma_{e}}\right)^{n}=\frac{1}{\tau_{2}\left(T_{2}\right)}\left(\frac{\sigma_{2}\left(T_{2}\right)}{\sigma_{e}}\right)^{n}$,

$\sigma_{2}\left(T_{2}\right)=\sigma_{1}\left(T_{1}\right) \sqrt[n]{\frac{\tau_{2}\left(T_{2}\right)}{\tau_{1}\left(T_{1}\right)}}$

With this relationship, the test results shown in Fig. 9(b) can be reproduced. The result of the calculation is shown in Fig. 10(a).

Fig. 11 shows the temperature and strain rate dependence of viscosity. The behavior of the visco-hypoplastic material model can be compared with the test results shown in Fig. 6 using the analogy of Maxwell model.

Fig. 11 correspond to Fig. 4, only the representation mode is different. Gajári made the assumption that the so-called Glaze Modulus (dark blue line, noted as extrapolated) corresponding to infinitely high frequency is temperature dependent.

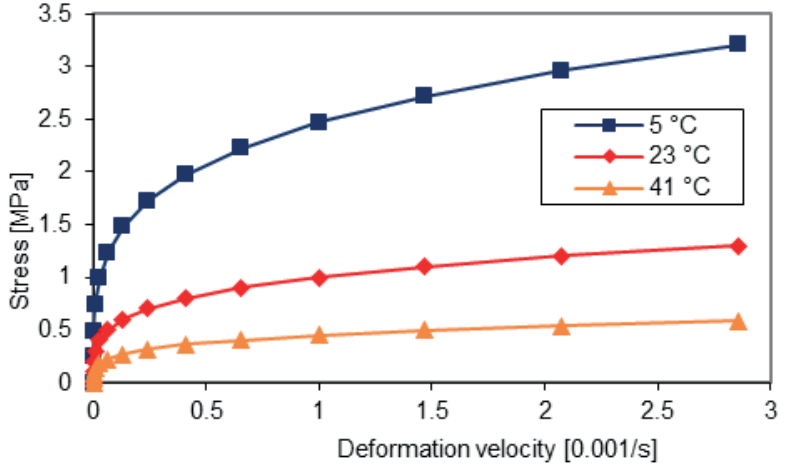

(a)

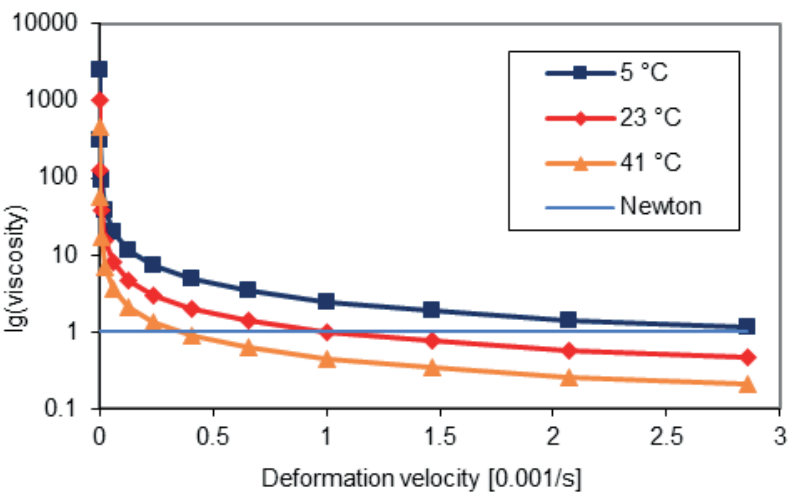

(b)

Fig. 10 Temperature dependent creep, numerically reproduced (a) Stress, (b) Viscousity

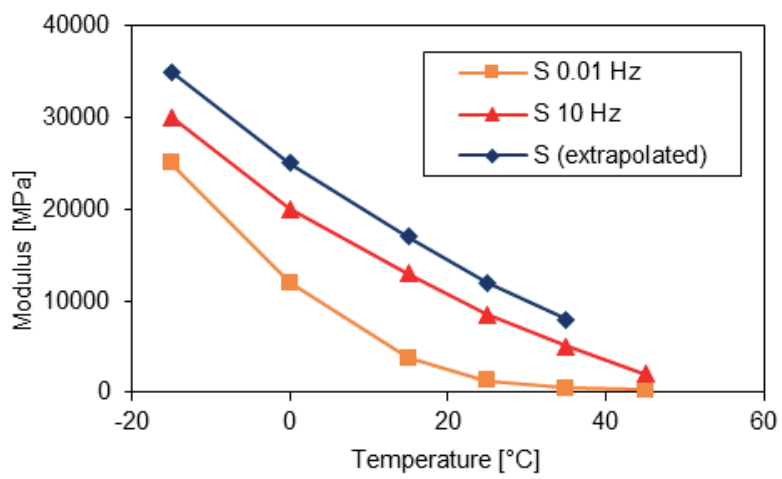

(a)

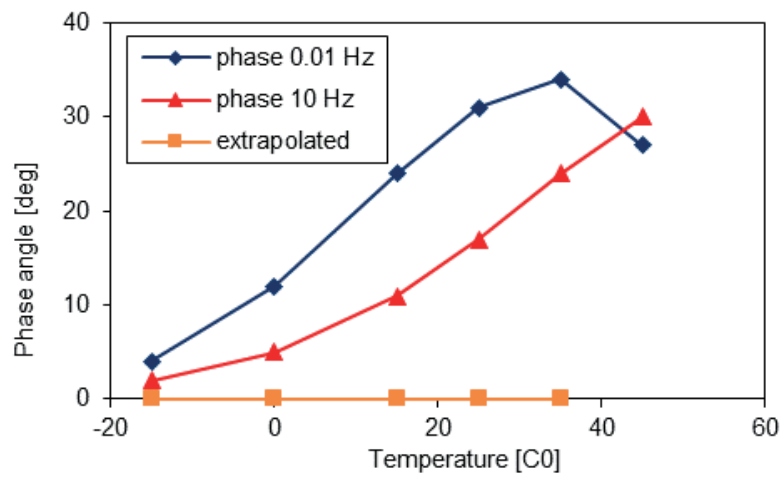

(b)

Fig. 11 Temperature and frequency dependent material parameters (a) Modulus, (b) Phase angle 
It can be concluded that:

- as the temperature increases, the modulus decreases at all frequencies,

- the modulus increases with increasing frequency and the phase angle decreases to a temperature of $35^{\circ} \mathrm{C}$,

- above $35^{\circ} \mathrm{C}$, the phase angle decreases at the lowest frequency.

The first statement can be easily reconciled with the visco-hypoplastic model: according to Eq. 34 the modulus is proportional to the pressure. In the Maxwell model, this is the Young's modulus, which decreases with increasing temperature due to the temperature dependent isotropic residual stress as shown in Fig. 8(a).

The second statement is consistent with the statement made in Section 3.2 for the Maxwell model: phase angle decreases with increasing frequency and the complex stiffness approaches the value of Young's modulus: $\omega \rightarrow \infty$, $\delta \rightarrow 0, S^{*} \rightarrow E$. The third conclusion can be explained by the fact that the phase angle decreases with increasing relaxation time, because $\tan \delta=\frac{1}{\omega t_{r}}$. But the relaxation time is $t_{r}=\frac{\mu}{E}$. As the temperature increases, both the viscosity and the modulus decrease. However, if the modulus decreases more than the viscosity with increasing temperature, the relaxation time will increase and therefore the phase angle may decrease.

It can be seen that qualitatively the visco-hypoplastic model is consistent with the observations. Quantitative compliance can only be demonstrated after the model parameters have been determined by laboratory tests and numerical simulations have been performed.

\section{Conclusions: theoretical and practical consequences}

The proposed visco-hypoplastic material model yields the following theoretical and practical consequences.

It has already been mentioned regarding the non-viscous hypoplastic material model that the version extended with intergranular strain should be used instead of the basic version when dealing with small-amplitude cyclic deformations $\left(\varepsilon<10^{-4}\right)[4]$. This modification also exists in the case of the visco-hypoplastic material model [27].

By cyclic deformation is meant an accumulated deformation arising from identically repeating phases. The phases are constantly followed by changes of direction. These reversals can be 180 or 90 degrees (a 0 degree "reversal" corresponds to monotonic loading). Stiffness increases with each reversal. If the subsequent unidirectional deformation does not exceed a certain magnitude, e.g., at 180 degrees it is $\varepsilon<10^{-4}$, and is followed by a reversal again and so on cyclically, then it is found that the deformations are reversible in addition to the high stiffness, i.e., they are not residual and they don't accumulate. If the unidirectional deformation is ten times that, then the stiffness drops to its one-tenth and strains accumulate due to plasticity. Harmonic loading is also a type of cyclic loading, and if the amplitude doesn't exceed the above-mentioned magnitude, no plastic strains will develop. This phenomenon is also called "small-strain" behavior. From micro-mechanical point of view, small deformations can be imagined as deformations of the grain contacts, while at larger deformations, the position of the grains to each other also changes, so the modulus is smaller, and the strains are not reversible but plastic. These experimental facts have been incorporated into hypoplastic material models $[4,27]$. This is one of the reasons why these models can be considered advanced.

The way to determine the complex modulus in uniaxial cyclic stress state has already been discussed in this paper. Not only the hypoplastic theory, but Gajári's measurement also confirms that the modulus is always a function of pressure or stress state. As a consequence, asphalt cannot have a master curve because it assumes that the modulus is only a function of frequency and temperature. Bitumen may have a master curve because its modulus is not pressure dependent. In the case of asphalt, the pressure dependence occurs due to the aggregate skeleton, which behaves as a three-dimensional structure.

The modulus of asphalt is not a material constant, but a quantity reflecting the actual condition. The widespread "uniaxial" approach of the modulus ignores the mechanics of granular materials. Neither the strength nor the modulus of asphalts can be tested with uniaxial loading. In the education of civil engineers, these principles are already taught as part of the basics of soil mechanics.

It has been illustrated that the theory of visco-hypoplasticity can be used to capture the most important aspects (i.e., stress state dependent stiffness and strength, viscous characteristic etc.) of rolled asphalt behavior, so the constitutive model is suitable to qualitative description of the material behavior. Another important advantage of visco-hypoplasticity is the fact that it originates from geotechnical engineering, so effective stress and pore pressure can be handled separately. This feature is especially useful when one wants to analyze the behavior of high temperature asphalt, where bitumen pressure may play an 
important role. In the framework of this currently ongoing research project specific laboratory tests will be performed to enable parameter calibration and quantitative analysis of asphalt behavior using visco-hypoplastic constitutive model.

\section{References}

[1] Fellin, W. "Hypoplasticity for beginners.", University of Innsbruck, Innsbruck, Austria, 2002. [online] Available at: https://www2.uibk. ac.at/downloads/igt/publications/_fellin/hypo_beginner.pdf

[2] von Wolffersdorff, P.-A. "A hypoplastic relation for granular materials with a predefined limit state surface", Mechanics of Cohesivefrictional Materials, 1(3), pp. 251-271, 1996. https://doi.org/10.1002/(SICI)1099-1484(199607)1:3<251::AIDCFM13>3.0.CO;2-3

[3] Kolymbas, D. "Introduction to Hypoplasticity, Advances in Geotechnical Engineering and Tunnelling 1", A.A. Balkema, Rotterdam, Netherlands, 1999.

[4] Niemunis, A, Herle, I. "Hypoplastic model for cohesionless soils with elastic strain range", Mechanics of Cohesive-frictional Materials, 2(4), pp. 279-299, 1998.

https://doi.org/10.1002/(SICI)1099-1484(199710)2:4<279::AIDCFM29>3.0.CO;2-8

[5] Fellin, W., Mittendorfer, M., Ostermann, A. "UMAT Implementation of Sand Hypoplasticity by UIBK", [online] Available at: https:// soilmodels.com/download/umat-hyposand-uibk

[6] Mašín, D. "A hypoplastic constitutive model for clays", International Journal for Numerical and Analytical Methods in Geomechanics, 29(4), pp. 311-336, 2005.

https://doi.org/10.1002/nag.416

[7] Bauer, E. "Calibration of a comprehensive hypoplastic model for granular materials", Soils and Foundations, 36(1), pp. 13-26, 1996. https://doi.org/10.3208/sandf.36.13

[8] Richter, E. "Nagytömörségủ aszfalt (HVA)" (High density asphalt (HDA)), Az Aszfalt, 26(1), pp. 27-30, 2018. (in Hungarian)

[9] Gajári, G. "Modellierung bleibender Verformungen des Asphalts mit einem hypoplastischen Stoffgesetz der Bodenmechanik" (Modeling permanent deformations of the asphalt with a hypoplastic material law of soil mechanics), PhD Thesis, Dresden University of Technology, 2012. [online] Available at: https://nbn-resolving.org/ urn:nbn:de:bsz:14-qucosa-103930 (in German)

[10] Gajári, G. "Az anyagi komponensek szerepe az aszfalt mechanikai viselkedésében" (The role of material components in the mechanical behavior of asphalt), Az Aszfalt, 25(1), pp. 51-55, 2017. (in Hungarian)

[11] Terzaghi, K. "Theoretical Soil Mechanics", John Wiley and Sons, New York, NY, USA, 2007. https://doi.org/10.1002/9780470172766

[12] Arand, W., Steinhoff, G., Eulitz, J., Milbradt, H. "Verhalten von Asphalten bei tiefen Temperaturen" (Behavior of asphalt at low temperatures), Institut für Straßenwesen der TU Braunschweig, Stuttgart, Germany, Project No. 5699, 1986. (in German)

\section{Acknowledgement}

The presented research has been sponsored by the 2018-1.3.1-VKE-2018-00008 project (Development of a Visco-Hypoplastic Asphalt Modell and an Analytical Methodology for Road Pavement Design), which is gracefully acknowledged.

[13] Arand, W. "Ermüdung von Asphalten bei Kälte" (Asphaltene fatigue in the cold), presented at Conference on the Properties of Asphalt Mixtures, Visegrád, Hungary, April 5, 2007. (in German)

[14] Cardona, D. A. R., Pouget, S., Di Benedetto, H., Olard, F. "Viscoelastic Behaviour Characterization of a Gap-graded Asphalt Mixture with SBS Polymer Modified Bitumen", Materials Research, 18(2), pp. 373-381, 2015. https://doi.org/10.1590/1516-1439.332214

[15] Tehrani, F. F., Absi, J., Allou, F., Petit, Ch. "Heterogeneous numerical modeling of asphalt concrete through use of a biphasic approach: Porous matrix/inclusions", Computational Materials Science, 69, pp. 186-196, 2013

[16] El Haloui, Y., El Omari, M., Absi, J., Tehrani, F. F. "Numerical Simulation of Fracture at Asphalt Mastic Materials", In: Proceeding of The International Conference on Optimization and Applications (ICOA2017), Meknès, Morocco, 2017, pp. 1-4.

[17] Iskakbayev, A., Teltayev, B., Alexandrov, S. "Determination of the Creep Parameters of Linear Viscoelastic Materials", Journal of Applied Mathematics, 2016, Article ID 6568347, 2016. https://doi.org/10.1155/2016/6568347

[18] Murali Krishnan, J., Rajagopal, K. R. "Triaxial testing and stress relaxation of asphalt concrete", Mechanics of Materials, 36, p. 849864,2004

https://doi.org/10.1016/j.mechmat.2003.08.003

[19] Taherkhani, H. "Compressive Creep Behaviour of Asphalt Mixtures", Procedia Engineering, 10, pp. 583-588, 2011. https://doi.org/10.1016/j.proeng.2011.04.097

[20] Huang, X., Zhang, Y. "A New Creep Test Method for Asphalt Mixtures", Road Materials and Pavement Design, 11(4), pp. 969991, 2011.

https://doi.org/10.1080/14680629.2010.9690315

[21] Aschenbrenner, L. "Mehrkomponenten-Modell zur Beschreibung des Deformationsverhaltens von Asphalt" (Multi-component model to describe the deformation behavior of asphalt), $\mathrm{PhD}$ Thesis, University of Braunschweig, 2006. (in German)

[22] Brodersen, B. O. "Modellierung des thermo-mechanischen Verbundverhaltens von Asphalt in Straßenaufbauten" (Modeling of the thermo-mechanical composite behavior of asphalt in road structures), PhD Thesis, University of Braunschweig, 2012. (in German)

[23] von Wolffersdorff, P.-A. "Ein hypoplastisches Stoffgesetz für granulare Materialien mit einer plastischen Fließbedingung für kritische Zustände" (A hypoplastic material law for granular materials with a plastic flow condition for critical states), PhD Thesis, The University of Karlsruhe, 1995. (in German) 
[24] Herle, I. "Hypoplastizität und Granulometrie einfacher Korngerüste" (Hypoplasticity and granulometry of simple grain structures), $\mathrm{PhD}$ Thesis, The University of Karlsruhe, 1992. (in German)

[25] ter Huerne, H. L. "Compaction of asphalt road pavements, using finite elements and critical state theory", PhD Thesis, University of Twente, 2004.

[26] Schofield, A., Wroth, P. "Critical State Soil Mechanics", McGraw-Hill, London, UK, 1968.

[27] Niemunis, A. "Extended hypoplastic model for soils", Habilitation thesis, Ruhr University Bochum, 2002.

[28] Bonnier, P. G. "Testing, Modelling and Numerical Analysis of the Mechanical Behaviour of Bituminous Concrete", PhD Thesis, TU Delft, 1993.

[29] Medani, T. O., Scarpas, A., Kolstein, M. H., Bosch, A., Molenaar, A. A. A. "Estimation of the ACRe material model parameters of mastic asphalt for orthotropic steel deck bridges", In: Wegbouwkundige Werkdagen 2002 (Proceeding of the Road Construction Work Days), Ede, Netherlands, 2002, pp. 475-491.

[30] Liu, X., Scarpas, A. "3D finite element modeling of polymer modified asphalt base course mixes", In: Loizos, A., Partl, M. N., Scarpas, T., Al-Qadi, I. L. (eds.) Advanced Testing and Characterization of Bituminous Materials, CRC Press, London, UK, 2009.

[31] di Benedetto, H. "Incremental constitutive law taking into account viscous and temperature effects: application to coated materials", In: Proceeding of International Conference on Constitutive Laws for Engineering Materials, Chongqing, China, 1989, pp. 343-348.

[32] Mašín, D. "Clay and Sand hypoplasticity UMAT and Plaxis implementations, including UMAT-Plaxis interface", [online] Available at: https:/soilmodels.com/download/plaxis-umat-hypoplas-zip/

[33] Kolymbas, D. "An outline of hypoplasticity", Archive of Applied Mechanics, 61, pp. 143-151, 1991. https://doi.org/10.1007/BF00788048
[34] Niemunis, A. "A visco-hypoplastic model for clay and its FE implementation", In: Resultats Recents en Mechanique des Sols et des Roches, XI Colloque Franco-Polonais en Mecanique des Sols et des Roches Appliquee (Recent results in soil and rock mechanics, Franco-Polish Symposium in Applied Soil and Rock Mechanics), Gdansk, Poland, Sept. 7-10, 1996.

[35] Niemunis, A., Nübel, K., Karcher, Ch. "The consistency conditions for density limits of hypoplastic constitutive law", Task Quarterly, 4(3), pp. 409-420, 2000.

[36] Bauer, E. "Calibration of a Comprehensive Hypoplastic Model for Granular Materials", Soils and Foundations, 36(1), pp. 13-26, 1996. https://doi.org/10.3208/sandf.36.13

[37] Butterfield, R. "A natural compression law for soils", Geotechnique, 29(4), pp. 469-480, 1979.

https://doi.org/10.1680/geot.1979.29.4.469

[38] Jin, Z., Yin, Y.-Z., Kotronis, P., Li, Z., Tamagnini, C."A hypoplastic macroelement model for a caisson foundation in sand under monotonic and cyclic loadings", Marine Structures, 66, pp. 16-26, 2019. https://doi.org/10.1016/j.marstruc.2019.02.002

[39] Guo, X., Peng, C., Wu, W., Wang, Y. "A hypoplastic constitutive model for debris materials", Acta Geotechnica, 11, pp. 1217-1229, 2016.

[40] Niemunis, A., Krieg, S. "Viscous behaviour of soil under oedometric conditions", Canadian Geotechnical Journal, 33(1), pp. 159-168, 1996. https://doi.org/10.1139/t96-031

[41] Perzyna, P. "Fundamental Problems in Viscoplasticity", Advences in Applied Mechanics, 9, pp. 243-377, 1966. https://doi.org/10.1016/S0065-2156(08)70009-7

[42] Olszak, W., Perzyna, P. "On thermal effects in viscoplasticity", Zeitschrift für angewandte Mathematik und Physik ZAMP, 20, pp. 676-680, 1969. https://doi.org/10.1007/BF01590623 